\title{
ANÁLISE DA ATUAÇÃO DE UM PROFISSIONAL DA SALA DE ATENDIMENTO MULTIFUNCIONAL NA PERSPECTIVA DA TEORIA DA APRENDIZAGEM SIGNIFICATIVA
}

\author{
ANALYSIS OF THE ACTIVITY OF A PROFESSIONAL IN THE \\ MULTIFUNCTIONAL SERVICE ROOM IN THE PERSPECTIVE OF THE \\ THEORY OF SIGNIFICANT LEARNING
}

\begin{abstract}
Rosângela Lopes Borges ${ }^{1}$
Marcos Fernandes-Sobrinho ${ }^{2}$

Resumo: A Teoria da Aprendizagem Significativa (TAS) de David Ausubel é uma das proposições da aprendizagem que visa aprimorar o processo educacional dos alunos. Nela se considera os conhecimentos prévios dos discentes, além da organização e estabilização de ideias. Este estudo tem como problemática a percepção e o uso da TAS pelos professores das Salas de Recursos Multifuncionais (SRM). Objetiva-se investigar como se dá o processo de ensino e aprendizagem dos alunos com Necessidades Educativas Especiais (NEE) e como o profissional de inclusão promove a Aprendizagem Significativa desses. Para isso, empregou-se uma pesquisa descritiva de cunho qualitativo, lançando mão do levantamento de informações, por meio de uma entrevista semiestruturada para com um profissional da SRM, que trabalha em uma escola estadual de um município do interior do Estado de Goiás/Brasil. Além disso, realizou-se uma observação sistemática, por três semanas, dos atendimentos matutinos a fim de perceber como ocorre o processo de ensino e aprendizagem no Atendimento Educacional Especializado (AEE) à luz da TAS. Conclui-se que a profissional entrevistada tem conhecimento da teoria em foco, que pondera as experiências vividas, enfatiza a interdisciplinaridade e estimula o desenvolvimento da autonomia dos estudantes. Entretanto, identificou-se a burocracia como empecilho à implantação de novas Salas de Recursos na localidade.
\end{abstract}

Palavras-chave: Significância do Ensino; Ausubel; Professor de AEE; Educação Inclusiva.

\begin{abstract}
David Ausubel Theory of Significant Learning (TSL) is one of the propositions of learning that aims to improve the educational process of students. It considers the students' previous knowledge, as well as the organization and stabilization of ideas. This study has as problematic the perception and the use of the TSL by the teachers of the Multifunctional Resource Rooms (MRR). The objective is to investigate how the teaching and learning process of students with special educational needs (SEN) is given and how the inclusion professional promotes their meaningful learning. For this, a qualitative descriptive research was used, using a semi-structured interview with a MRR professional, who works in a state school of a municipality of the interior of the State of Goiás/Brazil. In addition, a systematic observation was carried out for three weeks of the morning attendance in order to understand how the teaching and learning process occurs in the Specialized Educational Service (SES) in the light of the TSL. It is concluded that the professional interviewed has knowledge of the Theory in focus, which weighs the lived experiences,
\end{abstract}

\footnotetext{
${ }^{1}$ Mestranda do Programa de Pós-graduação em Educação Profissional e Tecnológica (ProfEPT) do Instituto Federal Goiano - Campus Morrinhos. Docente de graduação e pós-graduação pela Faculdade de Caldas Novas, Caldas Novas, Goiás, Brasil. E-mail: rosalb2@hotmail.com

${ }^{2}$ Doutor em Educação em Ciências e Matemática pela Universidade de Brasília (UnB). Docente do quadro permanente da área de Física Aplicada do Instituto Federal Goiano - Campus Urutaí. Credenciado junto aos Programas de Pós-Graduação em Ensino para a Educação Básica (PPGEnEB/IFGoiano), Urutaí, Goiás, Brasil; em Educação Profissional Tecnológica do Instituto Federal Goiano (ProfEPT/IFGoiano), Morrinhos, Goiás, Brasil; e em Gestão Organizacional da Universidade Federal de Goiás - Regional Catalão (PPGGO/UFG-RC), Catalão, Goiás, Brasil. E-mail: marcos.sbf@gmail.com
} 
emphasizes the interdisciplinarity and stimulates the development of students' autonomy. However, bureaucracy was identified as an obstacle to the implementation of new Resource Rooms in the locality.

Keywords: Significance of Teaching; Ausubel; Teacher of AEE; Inclusive education.

\section{Introdução}

A educação é um importante instrumento de ação transformadora da sociedade e do mundo. No decorrer do tempo surgiram diversas tendências pedagógicas e teorias da aprendizagem trazendo aprimorações à educação (MOREIRA, 1999). No entanto, o que se tem percebido é que as teorias ou tendências têm relação direta com os objetivos que se traçam, e esses envolvem distintas metodologias. Escolhe-se uma teoria mediante um objetivo, aplica-se uma metodologia em consonância com esse desígnio, a fim de alcançar sucesso no processo de ensino e aprendizagem.

Uma das teorias da aprendizagem que têm marcado a educação é a Teoria da Aprendizagem Significativa (TAS) de Ausubel (MOREIRA, 1999). Ela tem como meta principal a obtenção de um corpo arranjado de conhecimentos e a estabilização de ideias inter-relacionadas, que compõem a estrutura da disciplina a ser ensinada. Em sala de aula, esse ensino requer significados precisos e integrados por meio de compreensão e elaboração. Isso demanda do professor a capacidade de sistematização de princípios e recursos para a facilitação da aprendizagem expressiva.

Para que a escola cumpra uma de suas funções que é a de condutora da democracia é necessário que se ofereça uma aprendizagem significativa a todos os indivíduos (SAVIANI, 2008). Sendo assim, entendemos que seja um desafio ao sistema educacional atual, a aprendizagem de educandos com Necessidades Educativas Especiais (NEE) que estão inseridos no ensino regular (ROSA; PAPI, 2017).

Pensando nisso, foi implementada a Sala de Recursos Multifuncionais, Sala de Atendimento Educacional Especializado, ou ainda, Sala de AEE, que tem como objetivo o atendimento, em contra turno, dos alunos com deficiência e/ou dificuldade de aprendizagem. Nessa sala, o profissional do AEE, geralmente especializado em Educação Especial ou Inclusão promove uma aprendizagem individual, adequada e particularizada aos alunos que não conseguem acompanhar os demais (BRASIL, 2011). Entende-se que para realizar esse trabalho seja necessário que o docente parta dos conhecimentos prévios dos alunos e que lhe oferece uma aprendizagem que seja significativa e eficiente.

Diante da importância que Aprendizagem Significativa exerce sobre o ensino, e em especial na educação inclusiva, levantamos a seguinte problemática: Aprendizagem 
Significativa é considerada pelo professor da Sala de Recursos Multifuncionais durante a execução de suas atividades inclusivistas?

Logo, este estudo tem como objetivo investigar como ser dá o processo de ensino e aprendizagem dos alunos com NEE e como o profissional da inclusão promove sua Aprendizagem Significativa. Já que esta implica na valorização de conhecimentos anteriores dos sujeitos, para que novas estruturas mentais sejam arquitetadas (MOREIRA, 1999). Além disso, por meio de uma observação sistematizada pretendeu-se vislumbrar, na prática, como são considerados os cinco princípios educativos para uma Aprendizagem Significativa, dentro da Sala de AEE.

\section{Contexto histórico da educação especial}

Na Pré-História, a necessidade de sobrevivência impunha sobre o ser humano a habilidade de realizar atividades de caça, pesca. Além disso, segundo Rodrigues (2008, p. 7) "Estavam sujeitos às intempéries e aos animais selvagens". Não há registro de pessoas com deficiência nesse período, mas o autor supõe que esses eram deixados à própria sorte ou mortos por não conseguirem sobreviver sozinhos. Na Antiguidade, mais precisamente em Esparta e Atenas, o ideal de um corpo atlético e de rara beleza fez com que muitas crianças fossem abandonadas ou lançadas de rochedos.

Ainda de acordo com Rodrigues (2008), na Idade Média, a atitude das pessoas em relação àquelas com deficiência começa a mudar. Os milagres de Jesus, relatados na Bíblia, fizeram com que a Igreja assumisse o papel de acolher aos desvalidos. No entanto, a Inquisição católica foi responsável pela morte de várias pessoas que apresentavam distúrbios mentais, sendo estes confundidos com seres diabólicos, endemoniados ou hereges.

Apenas na Idade Moderna o médico Paracelso considerou em sua obra a deficiência como um problema médico. A ideia de hereditariedade como causa da deficiência só foi reconhecida na Idade Contemporânea, no século XVIII, por Foderé. No século XIX, Itard conseguiu comprovar a educação do menino Vitor, tido como selvagem. Mais tarde Pinel defende a deficiência como biológica. Até chegar à publicação da obra de Edouard Séguin, “Traitment Moral”, repleto de técnicas de Educação Especial. De lá para cá surgiram vários outros estudiosos como Johann Heinrich Pestallozzi e Maria Montessori que defendiam a capacidade de aprendizagem do "deficiente", no entanto, a 
inclusão ainda era assistencialista, com o objetivo de manter a ordem social ou o equilíbrio familiar (MAZZOTTA, 2005).

Jannuzzi (2004) explicita que a educação da pessoa com deficiência se concentrava no ensino de trabalhos manuais, isso para garantir meios de subsistência e assim desobrigar o Estado de uma futura dependência desses cidadãos. Em meados de 1890, os "anormais" começam a frequentar as escolas, no entanto, segregados em Instituições Especializadas, chamadas de escolas especiais ou em salas especiais, separados dos demais alunos. Em alguns momentos na literatura foi também intitulada de "educação de deficientes", "educação dos excepcionais" e "educação especial" (GONÇALVES et al., 2018).

Com a criação da primeira Lei de Diretrizes e Bases - LDB (BRASIL, 1961), em seu Artigo 88, é que se viu, pela primeira vez, a possibilidade de que os "excepcionais" fossem enquadrados no sistema geral de educação, a fim de integrá-los na comunidade. Posteriormente na segunda LDB (BRASIL, 1971), no Artigo 9, sugere que este público receba uma "tratamento especial". Em 1973, foi criado o primeiro Centro Nacional de Educação Especial (CENESP, posteriormente Secretaria da Educação Especial SEESP). Na sequência, a Constituição Federal do Brasil (BRASIL, 1988) que sugeriu uma educação para todos, e em seu Artigo 208, um atendimento educacional especializado aos "portadores de deficiência, preferencialmente na rede regular de ensino". A LDB (BRASIL, 1996), como se conhece hoje, assegura aos educandos com NEE: currículos, métodos e técnicas especializadas; terminalidade específica; professores com especialização adequada.

Vemos como necessária a distinção entre integrar e incluir. A integração trata-se de um entendimento de inserção parcial, porque o sistema prevê serviços educacionais segregados. Neste caso, a escola não muda como um todo, entretanto os alunos devem se adaptar às suas requisições. Já a inclusão questiona todo o sistema de ensino, não somente o da Educação Especial. Nela as escolas acolhem “[...] às diferenças sem discriminar, sem trabalhar à parte com alguns alunos, sem estabelecer regras específicas para se planejar, para aprender, para avaliar [...]" (MANTOAN, 2003, p. 16).

O que a autora explica é a mudança que ocorreu no processo de inclusão brasileira. Houve uma época em que sujeitos eram educados nas chamadas "Escolas Especiais" ou em estabelecimentos como a Pestalozzi e a Associação dos Pais e Amigos dos Excepcionais (APAE). Essa separação provocava uma distância entre esses e os demais alunos. Logo, foi proposto que os educandos com deficiência estudassem nas escolas 
regulares. No entanto, estabeleceu-se que isso ocorreria em uma "sala especial" segregando-os do convívio com os demais.

Nos dias atuais a legislação, no âmbito dos municípios brasileiros, dos Estados e da União, garantem os direitos dos cidadãos com deficiência. No entanto, a simples existência da lei não é suficiente para que os direitos sejam realmente respeitados (SILVA et al., 2018).

Atualmente, os alunos com e sem deficiência dividem as mesmas salas. As "escolas especiais" e as "salas especiais" foram eliminadas, quase por completo, do sistema educacional. Os estabelecimentos especializados como Pestalozzi e APAE oferecem atendimentos médicos, fisioterapêutico, psicológico, entre outros. Entretanto, seus clientes devem estar devidamente matriculados em uma instituição escolar. Salvo aqueles que por algum motivo médico sejam impossibilitados da convivência escolar. Tudo isso, de acordo com a determinação da Lei Brasileira de Inclusão da Pessoa com Deficiência (BRASIL, 2015) e do desafio da inclusão trazido pelo Plano Nacional de Educação (PNE 2014-2024).

De acordo com esse PNE, são considerados público-alvo da Educação Especial, na perspectiva da Educação Inclusiva: educandos com deficiência (intelectual, física, auditiva, visual e múltipla), transtorno global do desenvolvimento (Síndrome de Asperger ou Autismo) e altas habilidades ou superdotação. Vale ressaltar que os alunos com transtornos de aprendizagem (de origem neurológica) e dificuldades de aprendizagem (de origem psicopedagógica), não são necessariamente inclusos nesse processo, cabendo apenas às escolas o encaminhamento desses para o AEE.

Pereira (2009) realizou uma pesquisa com professores regentes dos anos finais do Ensino Fundamental a fim de compreender de que maneira ocorre a aprendizagem de educandos com Necessidades Educativas Especiais, incluídos no ensino regular. Pôde verificar que esses profissionais não se sentiam aptos a promover uma aprendizagem de qualidade para esses educandos. Segundo o autor, isso se deve à ausência de estrutura física, humana e teórica para fundamentar o docente em sua prática.

Diante do desafio de se ensinar um grupo tão heterogêneo, vê-se como necessária a capacitação contínua do educador. Esse deve utilizar os mais diversificados recursos pedagógicos para alcançar sucesso no processo de ensino e aprendizagem. Para isso, o docente (seja ele professor regular, de apoio ou profissional de AEE) deve lançar mão das teorias de aprendizagem para se obter um resultado significativo e eficiente. Soma-se a elas a Teoria da Aprendizagem Significativa, mais discutida na seção seguinte. 


\subsection{Aprendizagem significativa e inclusão}

A aprendizagem, de acordo com Gallina e Da Costa (2014), abrange um processo de mudanças de comportamento. Sendo esse adquirido por meio da experiência construída por fatores neurológicos, ambientais, emocionais e relacionais, resultantes da interação entre estruturas mentais e o meio ambiente em que se está inserido. É uma ação complexa, contínua, permanente e inerente em todo indivíduo e envolve aquele que aprende, o que ensina e a relação entre essas pessoas.

De acordo com Moreira (1999), a aprendizagem só faz sentido quando o significado daquilo que está sendo ensinado possua um intercâmbio com diferentes contextos reais. Isso ocorre, em especial, quando versamos a questão inclusiva, que normalmente deve buscar alternativas que instituam um ambiente estimulante com conteúdos claros e precisos (AUSUBEL; NOVAK; HANESIAN, 1982).

A Teoria da Aprendizagem Significativa de Ausubel é uma teoria cognitivista e construtivista sobre o processo de aquisição do conhecimento. Segundo Masini (2011a, p. 16) “É concebida como processo de compreensão, reflexão e atribuição de significado do sujeito, em interação com o meio social, ao constituir a cultura e por ela ser constituído". Essa se dá por recepção (o aluno recebe o conteúdo pronto) e por descoberta (o conteúdo deve ser descoberto pelo aluno) (MOREIRA, 1999).

Masini (2011b) desdobra os princípios da facilitação por meio da Teoria da Aprendizagem Significativa. Segundo ele, este se dá por meio da escolha do conteúdo que se vai aplicar. Podendo esta ser por ordenação hierárquica dos conceitos (Substantivamente) e apresentação do conteúdo à classe seguindo uma sequência lógica (Programaticamente). Sendo estes baseados no Princípio da Diferenciação Progressiva (as ideias mais gerais da disciplina são apresentadas antes e progressivamente) e no Princípio da Reconciliação Integrativa (o material de ensino visa explorar relações entre ideias).

Adão e Rangel (2013) explicam que a intenção da Aprendizagem Significativa é a intervenção na realidade e que sem essa finalidade ela se torna inócua. Então os autores defendem que se devem levar em consideração alguns princípios educativos mais contemporâneos como: a) considerar o estudante como sujeito de sua própria aprendizagem; b) reconhecer que o conhecimento é construído, progressivamente, por meio da atividade própria de cada sujeito e também pelas interações sociais; c) enfatizar a interdisciplinaridade e o desenvolvimento de competências; d) respeitar a diversidade 
dos estudantes, membros de um determinado grupo étnico-cultural e socioeconômico; e) estimular o desenvolvimento da autonomia do estudante, da sua participação na coletividade, promovendo a criticidade e a cidadania; f) considerar as experiências e vivências do estudante. Ou seja, os saberes já constituídos, como ponto de partida para as novas aprendizagens.

Segundo Budel e Meier (2012), os conceitos são propostos por meio de várias palavras, e isso dificulta a aprendizagem dos sujeitos com dificuldades na atenção de detalhes e/ou na interpretação de textos. Engloba, portanto, educandos com deficiência, transtornos e dificuldades de aprendizagem. Dessa forma, o uso de novos recursos para esses sujeitos alcancem o conhecimento é de grande relevância para a concretização da educação para todos.

A Teoria da Aprendizagem Significativa ainda tem introvertidas reflexões no campo da educação inclusiva. Isso decorre pelo simples fato de que o termo "inclusão", como explicitado no item 2 deste trabalho, está inserido há pouco tempo no contexto da reforma educativa. Araújo, Araújo e Silva (2016) defendem que a TAS é importante, pois propõe outro olhar sobre as relações escolares, trazendo novos significados sobre a anormalidade, ressaltando a competência cognitiva e os conhecimentos previamente contextualizados.

Lanuti (2015), em sua pesquisa, verificou a construção de estratégias para uma aprendizagem significativa e inclusiva na Matemática. Seu trabalho apontou que planejar situações de aprendizagem com atividades práticas, com base nos saberes prévios dos estudantes, utilizando diferentes espaços e materiais disponíveis na escola, proporciona a socialização e sistematização dos conhecimentos construídos.

Araújo, Araújo e Silva (2016) dizem que a educação dos alunos com deficiência, atualmente, solicita uma mudança na maneira de olhar, interagir e construir o conhecimento. Os autores defendem que não se pode falar de Aprendizagem Significativa sem ponderar do currículo. Já que esse na modalidade inclusiva tende a ser bem mais flexível, defendem que a decisão de adequação pedagógica e curricular deve ser tomada por uma equipe e não apenas pelo professor.

Gallina e Da Costa (2014) defendem que para que se consiga alcançar uma aprendizagem realmente significativa é necessária a atuação de um psicopedagogo. Para as autoras, as crianças com dificuldade em aprender tendem a se sentirem incompetentes, desmotivadas, e por vezes, agressivas. Desse modo, verifica-se que um profissional que 
conheça o problema e as possíveis estratégias de intervenção, possa contribuir com a análise do aluno e o assessoramento da escola.

A pesquisa de Masini (2011b) mostrou que houve uma aprendizagem significativa dos alunos com deficiência quando os professores: a) introduziram assuntos do cotidiano e situações familiares; b) procuraram recursos para que os alunos se interessassem pelo tema e estivessem atentos; c) buscaram as possibilidades de cada criança se comunicar cada um a seu modo; d) verificaram quais as facilidades e dificuldades dos alunos; e) ofereceram situações aos alunos para retomarem e exporem o que haviam feito, percebendo o que e onde haviam errado; f) estiveram atentas à disposição, interesses e experiência perceptiva do aprendiz, aproveitando situações emergentes; g) estiveram emocionalmente conectadas à criança.

\subsection{Sala de atendimento educacional especializado}

O Atendimento Educacional Especializado foi instituído primeiramente pela Constituição de 1988, no inciso III, do Artigo 208. Disposta na LDB Lei no 9.394/96, em seu Artigo 58, estabelecendo que a educação especial deve ser oferecida "preferencialmente" na rede regular de ensino, havendo, "quando necessário" serviços de apoio especializado. Mas, somente depois de 2008, sendo homologado o Decreto $\mathrm{n}^{\mathrm{o}}$ 6.571/08, foi que realmente começou a funcionar em algumas escolas a Sala de AEE. Posteriormente, esse foi revogado pelo Decreto $n^{\circ} 7.611 / 11$ que dispõe sobre a educação especial e o Atendimento Educacional Especializado, reforçado pelo PNE (2014-2024) e pela Lei Brasileira de Inclusão (2015).

O Conselho Nacional de Educação, por meio da Resolução CNE/CEB no 4/2009, estabelece as Diretrizes Operacionais para o Atendimento Educacional Especializado na Educação Básica, e define no Artigo 5, como deverão funcionar as Salas de AEE:

O AEE é realizado, prioritariamente, nas Salas de Recursos Multifuncionais da
própria escola ou em outra de ensino regular, no turno inverso da
escolarização, não sendo substitutivo às classes comuns, podendo ser
realizado, em centro de atendimento educacional especializado de instituição
especializada da rede pública ou de instituição especializada comunitárias,
confessionais ou filantrópicas sem fins lucrativos, conveniadas com a
secretaria de educação ou órgão equivalente dos estados, do Distrito Federal
ou dos municípios (BRASIL, 2009, p. 2).

Em 2010, o Ministério da Educação (BRASIL/MEC, 2010) laçou um manual de orientação "Programa de Implantação de Sala de Recursos Multifuncionais". Nele contém os aspectos legais e pedagógicos do Atendimento Educacional Especializado; 
objetivos e ações do programa de implantação de Salas de Recursos Multifuncionais; e condições gerais de implantação dessas salas. Segundo o documento, o profissional para atuar nesse âmbito deve ter formação inicial que o habilite para exercício da docência e formação específica na educação especial. Isso para que seja capaz de organizar estratégias pedagógicas, identificar e produzir de recursos acessíveis.

O profissional do Atendimento Educacional Especializado, conforme Silva e Arruda (2014), é o responsável por identificar as necessidades educacionais dos alunos com NEE e a partir disso criar um plano de ensino articulado e individualizado com o ensino regular da sala comum. Para isso, ele deve fazer uso dos recursos disponíveis na Sala de AEE, como: computadores, materiais pedagógicos, jogos educativos, alfabetos móveis, softwares, entre outros recursos de Tecnologia Assistiva; adaptando e desenvolvendo situações pedagógicas a fim de preparar o estudante para a vida em sociedade.

No Artigo 3, do Decreto 7.611/11 são explicitados os objetivos do Atendimento Educacional Especializado realizado nas Salas de Recursos Multifuncionais ou Sala de AEE:

I - prover condições de acesso, participação e aprendizagem no ensino regular e garantir serviços de apoio especializados de acordo com as necessidades individuais dos estudantes;

II - garantir a transversalidade das ações da educação especial no ensino regular;

III - fomentar o desenvolvimento de recursos didáticos e pedagógicos que eliminem as barreiras no processo de ensino e aprendizagem; e IV - assegurar condições para a continuidade de estudos nos demais níveis, etapas e modalidades de ensino (BRASIL, 2011, Artigo 3, p. 2).

Quanto ao Atendimento Educacional Especializado, a meta 4 do Plano Nacional de Educação (PNE 2014-2024) objetiva:

4.4. garantir atendimento educacional especializado em salas de recursos multifuncionais, classes, escolas ou serviços especializados, públicos ou conveniados, nas formas complementar e suplementar, a todos(as) alunos(as) com deficiência, transtornos globais do desenvolvimento e altas habilidades ou superdotação, matriculados na rede pública de educação básica, conforme necessidade identificada por meio de avaliação, ouvidos a família e o aluno [...] (BRASIL, 2014, p. 56).

Uma das práticas realizadas dentro da Sala de Atendimento Educacional Especializado que teve sucesso foi relatada por Carmello Neto (2015). De acordo com o autor, e também profissional de AEE, a prática surgiu das leituras que ele mesmo realizava com discentes atendidos. $\mathrm{O}$ pesquisador percebeu que os animais pré-históricos chamavam bastante a atenção de seus alunos, então resolveu aplicar a Aprendizagem 
Significativa na criação de um projeto "As pegadas do dinossauro". Fez uso dos mapas para avaliar o que os alunos já sabiam e o que poderiam aprender. Durante sua execução, os alunos e o especialista da Sala de Recursos realizaram: pesquisas, recortes, colagens, pinturas, quebra-cabeças, maquetes de dinossauro, entre outros.

Ingles e Godoy (2015) realizaram um trabalho de intervenção na Sala de Recursos Multifuncionais. O trabalho foi baseado nas diferentes linguagens (verbal, não verbal e mista) e no reconhecimento que os alunos fazem das mesmas em seu cotidiano. As autoras criaram um caderno pedagógico dividido em oito unidades, trabalhadas em forma de 16 sessões de duas horas cada. Como resultados obtiveram um crescimento e uma autonomia no uso das diferentes linguagens por parte dos alunos, e constataram que a ação coletiva em prol da aprendizagem significativa gera resultados mais eficientes.

Há de se ressaltar que o professor da Sala de Atendimento Educacional Especializado não trabalha sozinho. O resultado de seu trabalho tem uma íntima ligação com o professor regular da sala de aula, com a família dos alunos com deficiência, e com a própria gestão escolar (BRASIL, 2008).

É preciso que se prime por um planejamento que elenque as necessidades dos alunos, no entanto, Anache e Resende (2016) identificaram em sua pesquisa que os profissionais de AEE têm encontrado dificuldades em trabalhar em conjunto com o professor regente e que estes acreditam que as dificuldades de seus alunos são, em sua maioria, advindas de fatores de natureza endógena, esquecendo-se daqueles de ordem pedagógica, social, cultural e afetiva. Este último, de acordo com Moreira (1999, p. 169) faz parte da Teoria da Aprendizagem Significativa criada por Ausubel e desenvolvida por Novak, que defende que "Qualquer evento educativo implica uma ação para trocar significados e sentimentos entre professor e aluno".

Reiter (2015) defende que o indivíduo com deficiência seja altamente influenciado por seu ambiente. Dessa forma, ela sugere que o processo de Aprendizagem Significativa deve ter o envolvimento ativo dos alunos. Aconselha uma abordagem holística envolvendo cognição, emoção e comportamento, além de todos os ambientes em que estão inseridos como: bairro, clube social, escola, igreja, suas origens étnicas e nacionais, entre outros. 


\section{Procedimentos metodológicos}

Esta pesquisa se deu em dois momentos distintos. O primeiro, a elaboração de um referencial teórico referente ao contexto histórico da educação especial; a Aprendizagem Significativa e a inclusão; e também, sobre o surgimento das Salas de Atendimento Educacional Especializado. Já a segunda, uma pesquisa de campo que foi realizada com um profissional que trabalha na educação inclusiva.

Seguindo as ideias de Gerhardt e Silveira (2009) discriminaremos o tipo de pesquisa utilizada neste trabalho quanto aos seus objetivos, a sua abordagem e seus procedimentos. Em relação aos objetivos, esse estudo é caracterizado como uma pesquisa descritiva, pois se pretendeu registrar e descrever os fatos observados sem interferir neles. As pesquisas deste tipo, para Gil (2008, p. 28) “[...] têm como objetivo primordial a descrição das características de determinada população ou fenômeno [...]", neste caso, o profissional do AEE.

Quanto à abordagem, utilizamos uma abordagem qualitativa. De acordo com Prodanov e Freitas (2013, p. 128), nos dados qualitativos é realizada uma "[...] interpretação de fenômenos e atribuição de significados". Isso porque se pretendeu levantar dados qualitativos em relação ao profissional do Atendimento Educacional Especializado, ou seja, suas ideias e opiniões sobre a Aprendizagem Significativa e sua relação com as atividades propostas para promover o processo de ensino e aprendizagem dos alunos com NEE.

Quanto aos procedimentos, optou-se pelo estudo, análise e levantamentos (GIL, 2008) de informações sobre determinado indivíduo, a fim de estudar aspectos variados que sejam objeto da pesquisa. Nesse caso, pretendeu-se verificar o olhar que o profissional de AEE tem em relação à Teoria da Aprendizagem Significativa e como a utiliza no dia a dia na Sala de Recursos Multifuncionais.

A população refere-se aos profissionais do Atendimento Educacional Especializado de um município do interior do Estado de Goiás - Brasil. A cidade é composta por cerca de 60 escolas (entre municipais, estaduais e particulares), sendo que em apenas seis delas há uma Sala de AEE e um profissional especialista na área para o atendimento das crianças com deficiência. Optou-se pela "amostragem de conveniência" (GIL, 2008, p. 91) de apenas um participante, escolheu-se aquele que atende uma maior quantidade de alunos, trabalha há mais tempo nessa área e que tenha formação específica para essa atuação. 
Selecionou-se como instrumento para a coleta de dados, uma entrevista semiestruturada. Para Gil (2008, p. 109), trata-se de uma "[...] técnica em que o investigador se apresenta frente ao investigado e lhe formula perguntas, com o objetivo de obtenção dos dados que interessam à investigação". Ela foi composta inicialmente com cinco questões abertas, e se estenderam durante sua execução. Além disso, realizou-se também uma "observação sistemática" (GIL, 2008, p. 104) durante três semanas, dentro da Sala de Atendimento Educacional Especializado, a fim de averiguar a presença ou não da Aprendizagem Significativa na inclusão. Essa, também era composta por cinco itens a serem verificados, baseados nos cinco princípios educativos para uma Aprendizagem Significativa (ADÃO; RANGEL, 2013).

O período de aplicação da entrevista se deu no dia 07 de maio. As observações foram realizadas no período matutino, as terças e quintas, dos dias 08, 10, 15, 17, 22 e 24 do mesmo mês. Vale ressaltar que os alunos que foram atendidos nesse período são matriculados no período vespertino, de forma que frequentam a Sala de AEE em contra turno.

Em seguida, para apreciação e tratamento dos dados recolhidos com a aplicação da entrevista, como referencial metodológico de análise fizemos uso da proposta de Bardin (2011) sobre a análise de conteúdo em "três fases para a consecução da análise, que foram: (1) pré-análise; (2) exploração do material; e (3) tratamento dos resultados, inferências e interpretações" (SOUZA; AMAURO; FERNANDES-SOBRINHO, 2018, p. 187-189). Esses elementos foram analisados de maneira discursiva e reflexiva, correlacionando com a observação e com o próprio Referencial Teórico.

\section{Resultados e discussão}

A Escola pesquisada é uma das mais antigas desse município do interior do Estado de Goiás. Comporta atualmente 380 alunos, do $1^{\circ}$ ao $9^{\circ}$ ano do Ensino Fundamental, nos períodos matutino e vespertino, tem 38 funcionários no total. $\mathrm{O}$ ambiente é composto por nove salas de aulas, pátio coberto, quadra de esporte coberta e uma descoberta, banheiro adequado aos alunos com deficiência ou mobilidade reduzida, e uma Sala de Recursos Multifuncionais.

A Sala de Atendimento Educacional Especializado é coordenada por uma professora graduada em Pedagogia, quem tem especialização em Educação Especial e Inclusiva. Além disso, tem cursos de capacitação em Tecnologia Assistiva, braile, 
Interpretação em LIBRAS e Técnicas de AEE para Autistas. A docente tem 45 anos, é professora há 19 anos e trabalha como profissional da Sala de Recursos Multifuncionais desde 2013.

Sua sala recebe alunos de toda a escola e de outras duas escolas do município. São atendidos 32 alunos na Sala de Recursos Multifuncionais, divididos 13 no período matutino e 19 no período vespertino. As deficiências abrangem: cadeirantes, mobilidade reduzida, Autismo, Síndrome de Down, Cegueira e Surdez (os dois últimos estão matriculados em outra escola), além de outros que não têm necessariamente uma deficiência, mas que por apresentarem um relatório neuropsicológico puderam, também, ser atendidos pelo AEE.

O atendimento na Sala de Recursos Multifuncionais tem duração média de 30 minutos à uma hora, sendo esse duas vezes por semana. São previamente agendados em horário inverso ao que o aluno está matriculado. Há uma evasão bastante acentuada e os alunos faltam bastante, isso se dá, de acordo com a entrevistada, por não ter um responsável que o leve e espere-o ser atendido.

Buscamos saber como é a relação dessa profissional do AEE com os professores regentes e com a família dos alunos com deficiência. A professora nos respondeu que tem uma boa relação com os professores e com os pais, no entanto, relatou alguns obstáculos que dificultam o seu trabalho. Dentre eles: "Tenho dificuldades em sentar com o professor e elaborar um conteúdo ou uma avaliação, isso porque o tempo dentro da sala de aula é muito corrido".

Araújo, Araújo e Silva (2016) defendem que a decisão de adequação pedagógica e curricular deve ser tomada por uma equipe e não apenas pelo professor. Logo, entendemos que seja necessária essa relação de trocas de ideias entre professores regentes e o profissional do AEE.

Em relação aos pais, o problema se dá no contato com eles que, muitas vezes, não são presentes e nas dificuldades que alguns têm em aplicar, em casa, aquilo que é orientado pela especialista. Para a professora entrevistada, tanto a boa relação com os responsáveis quanto com os professores regentes são de suma importância para uma Aprendizagem Significativa, já que por meio dessa interação se pode conhecer o aluno, em ambientes distintos, trocar ideias e propor meios de intervenção.

Seguimentamos a análise da entrevista com a profissional de Atendimento Educacional Especializado em cinco tópicos que consideramos mais relevantes em relação ao que foi discutido inicialmente no Referencial Teórico sobre a Aprendizagem 
Significativa. Elaboramos o Quadro $1 \mathrm{com}$ base na perspectiva sintética da análise de conteúdo de Bardin (2011): a) assinalamos extratos das transcrições (em itálico); b) tecemos comentários e inferências; c) interpretamos os dados à luz de autores que embasaram este estudo.

\begin{tabular}{|c|c|}
\hline \multicolumn{2}{|c|}{ Aprendizagem Significativa e atuação profissional em ambiente de educação inclusiva } \\
\hline $\begin{array}{l}\text { O conhecimento } \\
\text { se dá por } \\
\text { recepção ou } \\
\text { descoberta? }\end{array}$ & $\begin{array}{l}\text { "Depende, quando é algo que é mais canteudista, a gente aplica mais por } \\
\text { recepção, mas quando é algo mais individual acabo utilizando mais a descoberta. } \\
\text { Ambas são eficientes, vai depender o que e para que esteja sendo utilizado”. } \\
\text { As duas formas são utilizadas, a opção entre uma e outra se dá de acordo com o } \\
\text { que se pretende ensinar e com o objetivo que se tem. Entendemos que o professor } \\
\text { do AEE deve ser capaz de perceber qual a melhor forma de se trabalhar com } \\
\text { determinado aluno e com determinadas dificuldades de aprendizagem. } \\
\text { Segundo Moreira (1999), o processo de conhecimento em meio à Teoria da } \\
\text { Aprendizagem Significativa pode se dar por meio da recepção, quando o discente } \\
\text { recebe o conteúdo pronto, ou ainda, por meio da descoberta, em que o professor } \\
\text { oferece a chance de ele descobrir sozinho. }\end{array}$ \\
\hline $\begin{array}{l}\text { Há um plano de } \\
\text { ensino articulado } \\
\mathrm{e} \\
\text { individualizado? }\end{array}$ & $\begin{array}{l}\text { "Sim, cada aluno tem um plano específico". } \\
\text { O Plano de Desenvolvimento Individualizado (PDI) é produzido em conjunto com } \\
\text { os relatos dos professores e dos pais. Esse documento é, geralmente, composto } \\
\text { em duas partes, na um roteiro de avaliação e, na segunda, na elaboração da } \\
\text { intervenção pedagógica especializada. Entendemos que esse plano enriquece e } \\
\text { facilita o processo de aprendizagem de alunos com NEE. } \\
\text { Silva e Arruda (2014) sugerem um plano de ensino articulado e individualizado. } \\
\text { Poker et al. (2013) elucida que o atendimento na Sala de Recursos deve estar } \\
\text { fundamentado nas habilidades e competências do aluno, considerando sua } \\
\text { condição específica para realizar determinadas tarefas. Em relação ao profissional } \\
\text { do AEE, Brasil (2008, p. 04) estabelece como uma de suas funções "Elaborar e } \\
\text { executar plano de atendimento educacional especializado, avaliando a } \\
\text { funcionalidade e a aplicabilidade dos recursos pedagógicos e de acessibilidade". }\end{array}$ \\
\hline & $\begin{array}{l}\text { "A interação emocional com a criança é de suma importância. Acredito que } \\
\text { consigo alcançar todos os meus alunos dessa forma". } \\
\text { Na troca de sentimentos é possível compreender o que esse aluno conhece como } \\
\text { percebe o mundo à sua volta e de que maneira interage com ele. Dessa forma, o } \\
\text { professor poderá traçar objetivos a serem alcançados no processo de ensino e } \\
\text { aprendizagem. As áreas emocional e afetiva são avaliadas também no PDI, citado } \\
\text { anteriormente. } \\
\text { A troca de significados e sentimentos entre professor e aluno, sugerida por Novak } \\
\text { e Ausubel, é defendida também por Moreira (1999). Selau (2010) ao se tratar de } \\
\text { educação escolar inclusiva diz que é responsabilidade do professor desenvolver } \\
\text { momentos de troca de afetividade e que onde não se consegue estabelecer um } \\
\text { vínculo afetivo "há uma dificuldade grande de se conseguir os limites" (p. 104). }\end{array}$ \\
\hline $\begin{array}{c}\text { Há } \\
\text { psicopedagogo } \\
\text { no AEE? }\end{array}$ & $\begin{array}{l}\text { "Não, mas seria bom ter um profissional que pudesse orientar mais nos } \\
\text { procedimentos de inclusão". } \\
\text { O trabalho de um psicopedagogo é de extrema importância para a inclusão. } \\
\text { Cabendo a esse a responsabilidade de avaliar e propor intervenções } \\
\text { psicopedagógicas, tanto no âmbito clínico (individual) quanto com relação à } \\
\text { instituição e as demais pessoas envolvidas nela. Acreditamos que a ausência desse } \\
\text { profissional na instituição escolar dificulta o processo de Aprendizagem } \\
\text { Significatica e consequentemente da inclusão. }\end{array}$ \\
\hline
\end{tabular}




\begin{tabular}{|l|l|} 
Gallina e Da Costa (2014) considera a aprendizagem como um processo de \\
mudanças de comportamento resultantes da interação entre estruturas emocionais, \\
mentais e o meio ambiente. Para os autores, para alcançar a aprendizagem \\
significativa (na inclusão) é necessária atuação de um psicopedagogo. Um \\
profissional que conheça os problemas de aprendizagem e estratégias de \\
intervenção poderá auxiliar consideravelmente o aluno e a escola.
\end{tabular}

Quadro 1: Análise da entrevista semiestruturada

Fonte: Produzido pelos autores

A fim de verificar como se dá Aprendizagem Significativa no trabalho da profissional do Atendimento Educacional Especializado, tivemos sua autorização para realizar uma Observação Sistemática (contendo cinco itens a serem averiguados). Esta se deu no período matutino, as terças e quintas, nos dias $08,10,15,17,22$ e 24 do mês de maio. Nesses dias são atendidos os alunos com cegueira, surdez e Síndrome de Down e mobilidade reduzida.

Os itens básicos da Observação foram criados baseados nas ideias de Adão e Rangel (2013), citados no referencial deste estudo. Buscou-se averiguar cinco princípios educativos para uma Aprendizagem Significativa: 1) Considerar as experiências e vivências do estudante; 2) Considerar o estudante como sujeito de sua própria aprendizagem promovendo envolvimento ativo dos alunos em tudo o que está sendo ensinado; 3) Enfatizar a interdisciplinaridade; 4) Respeitar a diversidade dos estudantes; 5) Estimular o desenvolvimento de sua autonomia.

O primeiro princípio educativo diz que o professor deve considerar as experiências e vivências dos estudantes. A professora, durante a entrevista, relatou que esse item é considerado por ela na execução e preparação de suas atividades. Na Observação pode-se constatar isso em dois momentos distintos: Primeiramente quando a aluna com Síndrome de Down foi desafiada a montar um quebra-cabeça, produzido juntamente com a professora, com a imagem de uma princesa, que ela mesma escolheu porque gosta. Outro fator que demonstrou a vivência do estudante é uma maquete sendo produzida pelo aluno que tem cegueira, da escola que ele estuda. Por meio de suas narrativas, a professora vai orientando-o e acrescentando itens a cada atendimento, conforme ele vai experienciando.

Nos conceitos de Aprendizagem Significativa, os subsunçores são um ponto cognitivo que permite um novo conhecimento. Um subsunçor é uma estrutura característica, na qual uma informação nova pode ser agregada por meio de experiências prévias (MOREIRA, 2010). Nos Parâmetros Curriculares Nacionais (BRASIL, 1998) sugere ações que potencializem a disponibilidade do aluno para a aprendizagem, ou seja, 
promover uma relação entre seus conhecimentos anteriores e o que está aprendendo sobre ele.

O segundo princípio educativo, sugeridos por Adão e Rangel (2013), considera que o estudante seja o sujeito de sua própria aprendizagem e sugere o envolvimento ativo dos alunos em tudo o que está sendo ensinado. Durante o período de Observação não foi possível constatar o envolvimento dos alunos no que estava sendo ensinado. Notou-se que a profissional do AEE direcionava os alunos nas atividades elaboradas por ela (docente) e não necessariamente por eles (discentes). Notou-se apenas que no caso do aluno com mobilidade reduzida (cadeirante), a professora deixou que ele escolhesse o que fazer e como fazer, já que a mobilidade das pernas e braços é bem limitada.

A instituição escolar, desde a sua criação, tem como principal missão a transmissão do conhecimento acumulado pela humanidade. Por muito tempo, esses conhecimentos chegavam aos alunos apenas pela voz dos professores. É preciso que os alunos sejam sujeitos participativos da construção de seu próprio conhecimento e, nesse sentido, Zabala (1998) defende que a maneira de ensinar não pode se limitar a um único modelo, mas que o aluno deve ser protagonista do seu conhecimento.

A interdisciplinaridade foi outro fator que foi identificado durante $o$ desenvolvimento da pesquisa. A profissional do AEE trabalha assuntos bem distintos e interdisciplinares com seus alunos. No momento da Observação foi possível presenciar assuntos como jogos eletrônicos, política, relações pessoais, meio ambiente e moda sendo utilizados como ponto de partida para o ensino de conteúdos. Nesse sentido, concordamos com Fernandes-Sobrinho e Santos (2014) quanto à defesa de que a interdisciplinaridade e a contextualização são importantes para ações educativas. Ambas podem favorecer qualitativamente o desenvolvimento de habilidades e competências consoantes à resolução de situações-problema e à aprendizagem de conceitos.

Constatou-se, também, que a professora do AEE utilizou imagens para explicar ao aluno com surdez o que eram os impactos ambientais. Para isso, ela utilizou o computador da Sala de Recursos, selecionou algumas imagens (de diversos contextos) em uma pasta, conforme o aluno passava as imagens, eles conversavam em Língua Brasileira de Sinais (LIBRAS). A docente explicou que "Tem sinais que nem eu e nem ele conhece, aí a gente cria e passa a utilizar. Muitas vezes, ele precisa me explicar o que viu na sala de aula para que eu possa explicar. Como a escola dele é outra, o trabalho fica mais difícil, mas a gente se vira bem". 
Inferimos que o trabalho dentro da Sala de Recursos Multifuncionais extrapola os limites da interdisciplinaridade. O trabalho feito nesse local aproxima mais da transdiciplinaridade (LEFF, 2001), uma abordagem que não se consegue distinguir os limites entre as disciplinas. Isso porque o professor de AEE não se atém apenas às disciplinas ministradas em sala de aula regular, mas faz uso assuntos do cotidiano para oferecer o conteúdo complementar e/ou suplementar.

O quarto princípio educativo para uma Aprendizagem Significativa, indicado por Adão e Rangel (2013) seria respeitar a diversidade dos estudantes. Este item pode ser verificado em, praticamente, todos os atendimentos. Isso ocorreu quando a professora optou por atendê-los individualmente; quando a atividade escolhida para ser aplicada é diferente dos demais; quando respeitou o tempo de resposta de cada aluno; quando no momento do atendimento do aluno com Autismo ela se sentou do outro lado da mesa, ao invés do lado do discente como nos outros atendimentos, já que este aluno prefere certa distância.

Corroborando com Carvalho (2004, p. 121), entendemos que a escola inclusiva é aquela que "inclua a todos, que reconheça a diversidade e não tenha preconceitos contra as diferenças, que atenda às necessidades de cada um e que promova a aprendizagem”. Logo, as instituições escolares devem abandonar o modelo de alunos homogêneos, incorporando a diversidade tanto no âmbito do trabalho com os conteúdos escolares quanto nas relações interpessoais.

O último item que foi apurado na Observação foi averiguar se a professora do Atendimento AEE estimula o desenvolvimento da autonomia do estudante. Verificou-se que a profissional instiga o aluno com pouca mobilidade a manusear objetos (colher e lápis) apesar de suas limitações; incentiva a aluna com Síndrome de Down a abotoar os botões da blusa de um boneco de pano; impulsiona o aluno com surdez a ir ao mercado para a mãe e interagir mais com os colegas de sala de aula; incentiva o aluno com cegueira a andar, pelos corredores da escola, sozinho.

A potencialização progressiva da autonomia dos alunos é defendida por Zabala (1998). Para o autor, potencializar a independência dos discentes é possibilitar que eles aprendam a aprender. Impulsionar essa autonomia significa serem capazes de utilizar, sem ajuda, os conhecimentos adquiridos, ou seja, colocá-los em prática em situações diferentes. Para isso, o autor sugere uma formação integral por meio de três dimensões: conceitual, procedimental e atitudinal. 


\section{Considerações finais}

Com o surgimento da Educação Especial foi se permitindo, aos poucos, que alunos com deficiência fossem matriculados no ensino regular com os demais. Os pressupostos legais, atualmente recomendam que esses frequentem aulas, normalmente, em turmas comuns e recebam atendimento especializado em contra turno. Este atendimento é realizado por um profissional formado na área, que presta serviços de complementação e suplementação pedagógicas para que os alunos possam acompanhar os demais colegas.

Para realizar esse trabalho de inclusão, entende-se que seja de suma importância o profissional de AEE lançar mão de uma gama de técnicas e teorias pedagógicas a fim de atingir seus objetivos. Por isso, o presente estudo teve como objetivo investigar o olhar de um desses profissionais sobre a Teoria da Aprendizagem Significativa. Foi possível verificar que a professora entrevistada tem consciência da importância do conhecimento prévio dos seus discentes; tem conhecimento da TAS e que a aplica, na medida do possível, em seus atendimentos especializados.

Além disso, averiguamos que a TAS faz parte da proposta do Atendimento AEE. A professora da Sala de Recursos Multifuncionais elabora um plano individualizado para cada aluno atendido e promove a troca de significados e sentimentos entre eles e com eles. O conhecimento, nesse caso, se dá tanto por recepção quanto por descoberta. Constatou-se ainda a ausência de um psicopedagogo para promover as avaliações e propor intervenções específicas diante das habilidades e limitações de cada estudante com Necessidade Educativa Especial.

Outro objetivo desta pesquisa foi vislumbrar, na prática, como a profissional da Sala de AEE aplica os princípios da Aprendizagem Significativa nos seus atendimentos. Pode-se constatar que ela pondera as experiências vividas pelos estudantes; considerar o estudante como sujeito de sua própria aprendizagem promovendo um envolvimento ativo dos alunos em tudo o que está sendo ensinado; as atividades propostas vão além da interdisciplinaridade chegando à transdisciplinaridade; respeitar a diversidade dos estudantes; estimular o desenvolvimento de sua autonomia dos alunos com Necessidade Educativa Especial. Percebemos que a professora tem uma relação íntima e emocional com seus alunos. Não foi possível verificar se o aluno é realmente sujeito de sua própria aprendizagem. Para isso, recomenda-se que sejam realizadas novas pesquisas que possam abarcar especificamente este item. 
Os obstáculos encontrados durante a pesquisa foi encontrar uma Sala de AEE bem equipada, com um profissional formado e que estivesse em pleno funcionamento. Mesmo se tratando de uma cidade com mais de 80 mil habitantes e cerca de 60 escolas (entre estaduais, municipais e particulares) são poucas as escolas que oferecem esse atendimento, mesmo sendo estabelecido por lei. A justificativa de algumas escolas é a burocratização para a implantação da Sala de Recursos que exige laudos médicos dos alunos que, muitas vezes, não apresentam e nem têm condições financeiras de obtê-lo.

\section{Referências}

ADÃO, N. M. L.; RENGEL, D. M. Competências para uma aprendizagem significativa: reflexões no contexto da educação profissional. E-Tech: Tecnologias para Competitividade Industrial, Florianópolis, v. 10, n. especial, p. 1-20, abr. 2013.

ANACHE, A. A.; RESENDE, D. A. R. Caracterização da avaliação da aprendizagem nas salas de recursos multifuncionais para alunos com deficiência intelectual. Revista Brasileira de Educação, Rio de Janeiro, v. 21 n. 66, p. 569-591, jul./set. 2016.

ARAÚJO, J. A. de.; ARAÚJO, M. J. A. de.; SILVA, M. A. Aproximações da teoria da aprendizagem significativa e a Educação Especial e Inclusiva. In: CONGRESSO INTERNACIONAL DE EDUCAÇÃO - CONEDU, 3, 2016, Natal/RN. Anais... Campina Grande - PB: Editora Realize, 2016, p. 01-06.

AUSUBEL, D. P.; NOVAK, J. D.; HANESIAN, H. Psicología Educativa: um ponto de vista cognoscitivo. 2. ed. México: Trilhas, 1982.

BARDIN, L. Análise de conteúdo. 1. ed. Lisboa: Edições 70, 2011.

BRASIL. Lei n ${ }^{\circ}$ 4.024, de 20 de dezembro de 1961. Fixa as Diretrizes e Bases da Educação Nacional. Diário Oficial da União, Brasília, 27 dez. 1961.

BRASIL. Lei no 5.692, de 11 de agosto de 1971. Diretrizes e Bases para o ensino de $1^{\circ}$ e $2^{\circ}$ graus, e dá outras providências. Diário Oficial da União, Brasília, 12 ago. 1971.

BRASIL. Constituição (1988). Constituição da República Federativa do Brasil. Organização de Alexandre de Moraes. 16. ed. São Paulo: Atlas, 2000.

BRASIL. Lei de Diretrizes e Bases da Educação Nacional. Lei número 9.394, 20 de dezembro de 1996. Diário Oficial da União, Brasília, 23 dez. 1996.

BRASIL. Secretaria de Educação Fundamental. Parâmetros Curriculares Nacionais. Brasília, DF, 1998.

BRASIL. Resolução CNE/CEB n ${ }^{\circ}$ 4/2009, estabelece as Diretrizes Operacionais para o Atendimento Educacional Especializado na Educação Básica. 2009. Disponível em: <http://portal.mec.gov.br/dmdocuments/rceb004_09.pdf >. Acesso em: 30 maio. 2018.

BRASIL. Ministério da Educação e Cultura. Manual de Orientação: Programa de Implantação de Sala de Recursos Multifuncionais. MEC/SEE, 2010. Disponível em:

$<$ http://portal.mec.gov.br/index.php?option=com_docman\&view=download\&alias=9936- 
manual-orientacao-programa-implantacao-salas-recursos-multifuncionais \&Itemid=30192>. Acesso em: 30 maio. 2018.

BRASIL. Decreto n ${ }^{\circ}$ 7.611, de 17 de novembro de 2011. Dispõe sobre a Educação Especial, o Atendimento Educacional Especializado e dá outras providências. Diário Oficial da União, Brasília, 18 nov. 2011.

BRASIL. Plano Nacional de Educação (PNE 2014-2024). Planejando a Próxima Década Conhecendo as 20 Metas do Plano Nacional de Educação. Disponível em: <http://pne.mec.gov.br/images/pdf/pne_conhecendo_20_metas.pdf>. Acesso em: 30 maio. 2018.

BRASIL. Lei $n^{\circ} 13.146$, de 6 de julho de 2015. Institui a Lei Brasileira de Inclusão da Pessoa com Deficiência (Estatuto da Pessoa com Deficiência). Diário Oficial da União, Brasília, 07 jul. 2015.

BUDEL, G. C.; MEIER, M. Mediação de aprendizagem na educação especial. 1. ed. Curitiba: Ibpex, 2012.

CARMELLO NETO, A. A importância da aprendizagem significativa na educação especial. Boas Práticas na perspectiva da Educação Especial Inclusiva, São Paulo, v. 1, 2015. Disponível em: <http://cape.edunet.sp.gov.br/cape_arquivos/BoasPraticas/IMPORTANCIAAPRENDIZAGEM SIGNIFEDUCESP.pdf>. Acesso em: 30 maio. 2018.

CARVALHO, R. E. Removendo Barreiras para a aprendizagem. 4. ed. Porto Alegre: Mediação, 2004.

GALLINA, C. P.; DA COSTA, G. M. T. A atuação do psicopedagogo: importância e contribuição para uma aprendizagem significativa. Revista Educação do IDEAU, Bagé, v. 9, n. 20, p. 1-13, jul./dez. 2014.

GERHARDT, T. E.; SILVEIRA, D. T. Métodos de pesquisa. 1. ed. Porto Alegre: Editora da UFRGS, 2009.

GIL, A. C. Como elaborar projetos de pesquisa. 4. ed. São Paulo: Atlas, 2008.

GONÇALVES, J. P. B. et al. Estudo sobre as condições de inclusão em uma escola estadual na cidade de Caldas Novas nos últimos 13 anos. Ciclo Revista: experiências em formação no IF Goiano, Goiânia, v. 3, n. 1, p. 1-12, 2018.

INGLES, M. A.; GODOY, M. A. B. Aprendizagem significativa nas salas de recursos multifuncionais por meio das diferentes linguagens. In: CONGRESSO NACIONAL DE EDUCAÇÃO-EDUCERE E SEMINÁRIO INTERNACIONAL SOBRE PROFISSIONALIZAÇÃO DOCENTE - SIPD, XII e V, 2015, Curitiba/PR. Anais... Curitiba/PR: PUC/PR, 2015, p. 25266- 25280.

FERNANDES-SOBRINHO, M.; SANTOS, W. L. P. dos. Inserções da interdisciplinaridade e contextualização em itens do Enem/2013 com potencial ao enfoque CTS. Uni-pluri, Medellin, v. 14, n. 3, p. 94-101, 2014.

JANNUZZI, G. M. A educação do deficiente no Brasil: dos primórdios ao início do século XXI. 3. ed. Campinas: Editora Autores Associados Ltda, 2004. 
LANUTI, J. E. O. E. Educação Matemática e Inclusão Escolar: a construção de estratégias para uma aprendizagem significativa. 2015. 127f. Dissertação (Mestrado em Educação) Faculdade de Ciências e Tecnologia, Universidade Estadual Paulista, Presidente Prudente, 2015.

LEFF, E. Saber ambiental, Sustentabilidade, Racionalidade. 4. ed. Petrópolis: Vozes, 2001.

MANTOAN, M. T. E. Inclusão escolar: o que é? por quê? como fazer? 1. ed. São Paulo: Moderna, 2003.

MAZZOTTA, M. J. S. Educação especial no Brasil: história e políticas públicas. 5. ed. São Paulo: Cortez, 2005.

MASINI, E. F. S. Aprendizagem significativa: condições para ocorrência e lacunas que levam a comprometimentos. Aprendizagem Significativa em Revista/Meaningful Learning Review, São Paulo, v. 1, n. 1, p. 16-24, jul. 2011 a.

MASINI, E. F. S. A facilitação da aprendizagem significativa no cotidiano da Educação Inclusiva. Aprendizagem Significativa em Revista/Meaningful Learning Review, São Paulo, v.1, n. 3, p. 53-72, 2011 b.

MOREIRA, M. A. Teorias da Aprendizagem. 1. ed. São Paulo: EPU, 1999.

MOREIRA, M. A. Mapas conceituais e aprendizagem significativa. 1. ed. São Paulo: Centauro Editora, 2010.

PEREIRA, E. P. Um olhar sobre a aprendizagem de educandos com necessidades educacionais especiais incluídos nos anos finais do Ensino Fundamental. In: CONGRESSO NACIONAL DE EDUCAÇÃO E ENCONTRO SUL BRASILEIRO DE PSICOPEDAGOGIA, IX e III, 2009, Curitiva/PR. Anais... Curitiba/PR: Editora Champagnat, 2009, p. 3882- 3895.

POKER, B. et al. Plano de Desenvolvimento Individual para o Atendimento Educacional Especializado. 1. ed. São Paulo: Cultura Acadêmica/Marília/Oficina Universitária, 2013.

PRODANOV, C. C.; FREITAS, E. C. de. Metodologia do trabalho científico: métodos e técnicas da pesquisa e do trabalho acadêmico. 2. ed. Novo Hamburgo: Feevale, 2013.

REITER, S. Meaningful Learning in Special Education Teaching and Learning Based on the Cycle of Internalized Learning: A Review. Open Journal of Social Sciences, Chhattisgarh/India, v. 3, n. 09, p. 103-111, sept. 2015.

ROSA, K. B.; PAPI, S. O. G. Os professores e os desafios da inclusão de alunos com deficiência no ensino comum. In: CONGRESSO NACIONAL DE EDUCAÇÃO - EDUCERE, 13, 2017, Curitiba/PR. Anais... Curitiba/PR: PUC/PR, 2017, p. 13831- 13846.

RODRIGUES, O. M. P. R. Educação especial: história, etiologia, conceitos e legislação vigente. 1. ed. Bauru: MEC/FC/SEE, 2008.

SAVIANI, D. Escola e Democracia. Edição Comemorativa. Campinas: Autores Associados, 2008.

SELAU, B. Inclusão na sala de aula. 2. ed. São Luiz/MA: Edufma, 2010.

SILVA, A. P. M.; ARRUDA, A. L. M. M. O Papel do Professor Diante da Inclusão Escolar. Revista Eletrônica Saberes da Educação, São Roque, v. 5, n. 1, p. 1-29, 2014. 
SILVA, D. A. et al. M. Educação Inclusiva em Ciências e Matemática: levantamento de publicações pertinentes ao tema em periódico especializado entre 2012 e 2017. Multi-Science Journal, Ururaí, v. 1, n. 12, p. 36-40, abr. 2018.

SOUZA, P. V. T.; AMAURO, N. Q.; FERNANDES-SOBRINHO, M. Modelizações astronáuticas na perspectiva da educação CTS: proposta de atividade integradora ao ensino de ciências. Química Nova na Escola, São Paulo, v. 40, n. 3, p. 186-195, 2018.

ZABALA, A. A prática educativa: como ensinar. 1. ed. Porto Alegre: ARTMED, 1998.

Recebido em: 30 de setembro de 2018 .

Aceito em: 10 de dezembro de 2018. 